\title{
Paragrammatisms: A Longitudinal Study of an Italian Patient
}

\author{
Brian Butterworth \\ Department of Psychology, University College London, London, U.K. \\ Marta Panzeri, Carlo Semenza and Tiziana Ferreri \\ Dipartimento di Psicologia Generale, Università degli Studi di Padova, \\ Padova, Italy
}

The speech of an Italian fluent aphasic, R.B., was analysed for paragrammatisms (grammatical errors), using the methods employed by Butterworth and Howard (1987). Unlike that study, samples of speech were collected over 7 months in the evolution of R.B.'s condition. Analysing speech from a language with a richer inflexional system than English, and assessing the changes in the pattern of errors over time allows a more stringent test of Butterworth and Howard's proposed explanation for the incidence of grammatical errors in fluent aphasia-an across-the-board impairment of control, rather than specific deficits in grammatical processes, monitoring or lexical selection. R.B.'s speech was similar to that of Butterworth and Howard's patients, and showed no consistent trends in the pattern of errors over time, with one minor exception. These data were interpreted as consistent with an impairment of control, and inconsistent with other candidate accounts.

\section{INTRODUCTION}

Butterworth and Howard (1987) have recently produced the first systematic analysis of a large number of paragrammatisms (i.e. grammatical errors) in the speech of fluent aphasic patients (226 grammatical errors in nearly 11,000 words from five patients). Their major finding was that aphasic errors appear to be of the same types as those found in normal

Requests for reprints should be addressed to Brian Butterworth, Department of Psychology, University College London, Gower Street, London WC1E 6BT, U.K.

Dr David Howard and Dr Lorraine $\mathrm{K}$. Tyler made many helpful suggestions on earlier drafts of this paper. This work was supported by grants from NATO (No. 86/0751) to Brian Butterworth, Carlo Semenza and Marta Panzeri, and from the CNR to Unita 14, Scienze del Comportamento, and from Ministero della Pubblica Istruzione to Carlo Semenza.

(C) 1990 Lawrence Erlbaum Associates Lid and V.S.P. Publications 
speakers. The patients simply produced more of them. They concluded that their patients suffered no deficit of knowledge of syntax or morphology, nor were particular stages of the production process impaired; rather, these patients suffered from an across-the-board impairment of "control", a set of functions specified in Butterworth's (1980) model of speech production. Transient control malfunctions are, by this account, responsible for grammatical errors in both normal and aphasic speech.

The term "paragrammatism" was introduced by Kleist (1916) to denote an aphasic syndrome whose signature is an expressive disturbance characterised by the presence of confused and erroneous grammatical structures in speech. For Kleist, this syndrome was an aspect of Wernicke's aphasia, where patients would show fluent speech and impaired comprehension and whose neural damage would be located in the temporal region. He contrasted paragrammatism with "agrammatism", an aspect of Broca's aphasia. In this syndrome, speech would be dysfluent, comprehension relatively spared and damage located in the frontal region. Unlike paragrammatic cases, the utterances of agrammatic patients were characterised by errors of omission, rather than commission: omissions of grammatical morphemes, reduced or absent syntactic structure and "telegraphic" style.

Clearly implied in Kleist's distinction of the two patterns of speech impairment are two distinct functional impairments. This immediately raises the problem of how to classify speech errors in terms of underlying malfunctions. Intuitively, the appearance of grammatical errors in speech may arise as a substitution error by a word of the wrong grammatical category (e.g. by a noun for a verb), or by the presence of the incorrect conjugation of a verb or the incorrect declension of a noun, any of which may be the result of an error of lexical selection, rather than the malfunction of some strictly grammatical process. An omission similarly may be due to a selection failure, and indeed omissions may also give the appearance of structural error. In general, it will be a delicate matter to assign some particular error to reduced, agrammatic, rather than to confused, paragrammatic syntax, or to some other cause. A difficulty with studying Englishspeaking patients is the lack of surface information as to the intended grammatical structure of an utterance. Most nouns and verbs, for example, share the same form (chair, palm, book, etc., can be both nouns and verbs). English has no explicit markers on nouns or adjectives for case, and few markers on verbs for tense, mood, number or person. Derivational morphology is, at best, an intermittent and uncertain guide as to the intended grammatical category of the word. It is possible, therefore, that Butterworth and Howard's (1987) analysis misrepresented to some extent the distribution of errors.

If functional aetiology sharply differentiated paragrammatic and agrammatic speech, one would expect a patient to present either agrammatic 
errors or paragrammatic errors, but not both. However, from Kleist onwards, it has been noted that agrammatic patients sometimes produce confused rather than reduced syntax and morphology, and that paragrammatic patients produce errors of omission as well as of commission (Isserlin, 1922; Miceli, Silveri, Romani, \& Caramazza, 1989; Weisenburg \& McBride, 1935; see de Bleser, 1987, for a review of the early German work). Kleist referred to these patients as "mixed cases", which seemed to imply that they suffered from two functional impairments.

Theoretically, the issue is to locate as precisely as possible, the impairments responsible for an error, or for a pattern of errors, in a model of the speech production processes. Systematic analyses of errors in the speech of normal speakers has led to the location of different types of error at different points in the production process (e.g. Fromkin, 1973; 1980; Garrett, 1975; 1980; 1982). Occasionally, errors attributed to incorrect lexical selection, or to relatively early exchanges of words in their grammatical relations and to shifts of morphemes in late assembly processes, will lead to ungrammatical utterances, but little attention has been paid to specifically grammatical errors. Recently, attempts have been made to apply both the models and the techniques derived from normal speech to the analysis of agrammatic output, with a number of proposals for the functional locus of this disorder (Bradley, Garrett, \& Zurif, 1980; Lapointe, 1985; Schwartz, 1987). Much less attention has been paid to explaining the speech of paragrammatic patients. Pick (1931), in one of the few available accounts, proposed two loci in a simple sequential stage model of speech production: Errors of syntactic structure were due to a failure of inhibition at the stage of the formation of sentence schemata, whereas errors of grammatical morphology were due to failure of inhibition at a later stage, that of "grammaticisation", where grammatical morphemes were appended to words already chosen and fixed in their final sentence positions. Lexical selection errors (verbal paraphasias), on the other hand, were attributed to the quite separate stage of the production process where word choices are made.

Butterworth and Howard (1987) analysed the spontaneous speech of five fluent patients and four normal comparison subjects. Grammatical errors were classified into (1) open-class errors of category and subcategory substitutions, omissions and additions, (2) closed-class errors of category and subcategory substitutions, omissions and additions, (3) inflexional errors, (4) constructional errors (e.g. word-order errors, sentence blends) and (5) residual errors (see the Method section for more details). Along with an outline of the three classes of explanation, and the predictions that follow from them, we add a brief summary of Butterworth and Howard's main findings

They outlined three types of explanatory hypothesis that were consistent 
with the data, available before their study, and consistent with current ideas about the nature of speech production processes and their disturbances in aphasia. For each type of explanation, predictions were derived as to the pattern of errors that should be observed. We summarise below the three classes of explanatory hypothesis, together with the predictions that follow from them. In addition, we briefly summarise their main findings in so far as they are relevant to the predictions.

\section{Syntactic Deficit Hypothesis}

In one version, it is hypothesised that the rules for generating phrase markers have been partly lost or corrupted. This would predict a quite general failure to produce grammatically correct output, with perhaps only simple, heavily used constructions being produced correctly. According to Garrett's (1975; 1980) model of production, this impairment would involve those morphemes carrying the major burden of grammatical structureclosed-class words and bound grammatical morphemes. In Pick's version, there need be no loss or corruption, but rather failure to inhibit incorrect sentence schemata and grammaticisations.

Predictions. Although a grammatically incorrect sentence could arise through choosing the wrong word, lexical selection errors should not exhaust the types of erroneous construction observed. There should be a particular failure to use closed-class words and grammatical morphemes correctly. Correct long and complex sentences should not be observed.

Findings. Long and complex sentences were produced correctly by all five patients. Closed-class words were involved in error no more frequently than open-class words.

\section{Lexical Deficit Hypothesis}

The lexical deficit hypothesis, but with no deficit of syntax as such. It is widely held that fuent aphasics have particular difficulty with word-finding: They make frequent verbal paraphasias, and they use neologisms and circumlocutions in place of the target word (Butterworth, 1979). Typically, the problematic targets are low-frequency, open-class words (Butterworth, 1979; Newcombe, Oldfield, \& Wingfield, 1965).

Predictions. Erroneous constructions should be explicable in terms of the substitution of one or two open-class words per sentence. The incidence of clear lexical errors should correlate with the incidence of paragrammatisms. 
Findings. Many sentences could not be explained in terms of the substitution of one or two words; open-class words were involved only as often as closed-class words; paragrammatisms did not correlate with lexical errors (defined as neologisms) across subjects.

\section{Monitoring Impairment Hypothesis}

In normal speakers, monitoring prevents overt errors in speech production, while in paragrammatic patients it is assumed that this mechanism is faulty. According to Levelt $(1983 ; 1989)$, mechanisms serving the comprehension of other people's speech, also serve to check one's own speech prior to output. This can be carried out either on the phonological plane, or at the pre-linguistic message level. In principle, monitoring checks for all types of error and unintended output, though it is possible that some errors are easier to identify and suppress than others. Evidence as to which these might be is scanty. Observed errors, however, may be a joint function of the efficiency of the monitor and the underlying rate of errors. How to separate these two components is unclear.

Predictions. Patients with poor comprehension should produce more errors of all types, including paragrammatisms, than those with better comprehension.

Findings. There was no relation between comprehension scores and rate of paragrammatisms; nor was there a correlation between the rate of lexical errors (neologisms) and paragrammatisms.

\section{CONTROL IMPAIRMENT}

Given that each of these potential explanations appear to be disconfirmed by the evidence, Butterworth and Howard proposed a fourth explanation in terms of an across-the-board impairment of control mechanisms, and we devote rather more space to explaining this. According to Butterworth (1980; 1982; 1985) and Butterworth and Howard (1987), the speech production system is held to consist of independent component processes, or "modules" (in Shallice's, 1988, pp. 20, 258-260, sense) (see Fig. 1). Each module is subject to a control system (designated by an oval in Fig. 1), which has four functions:

1. An instruction to initiate the operation of the module (e.g. lexical selection, or generation of phrase markers by the syntactic module).

2. A transfer function such that the output(s) from a module or modules "dominating" (see Butterworth, 1980, for a definition) a given module 


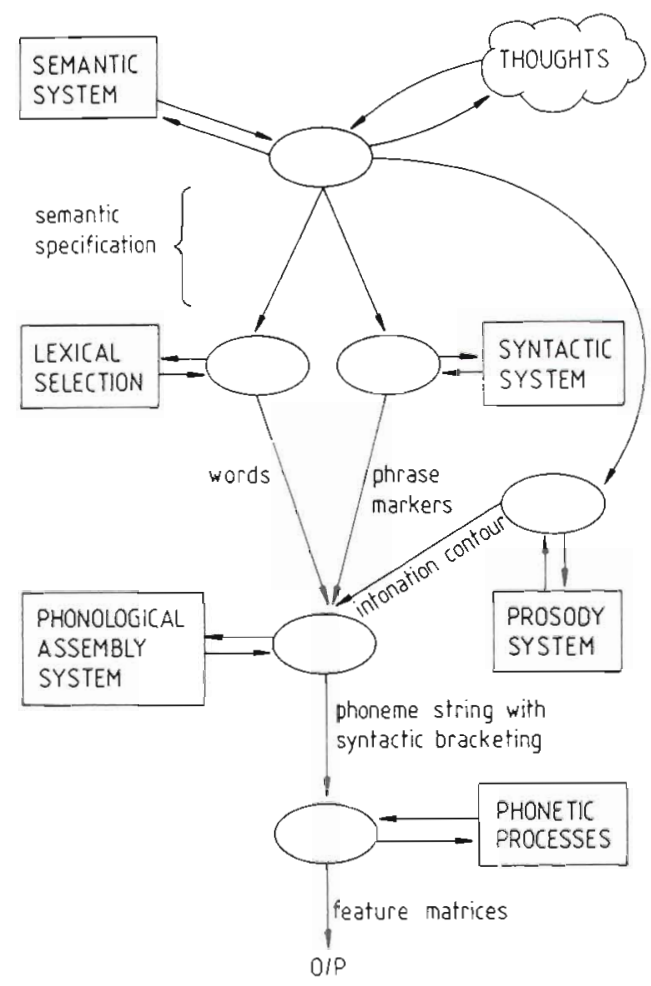

FIG. 1. A model of speech production (after Butterworth, 1980). Boxes indicate component processes, ovals indicate control systems associated with component processes and arrows indicate the flow of information. See text for further details.

is accessed and used to determine the operation of that module (e.g. output from the semantic module is accessed for interpretation by the syntactic module).

3. A check that the output from a module is correct (see Butterworth, 1982, for details).

4. An instruction to terminate the operation of the module.

Butterworth and Howard $(1987$, p. 33) explain the observed pattern of errors as follows:

Globally, the independence of error types follows from the independence of the modules and the presence of all aphasic error types in the comparison corpus will be a consequence of transient control malfunctions rather than permanent malfunctions in the modules themselves. Notice that these accounts are not vacuous: if, for example, particular error forms were found in one patient, but nowhere else, and if, moreover, the constructions found in errors were not found produced correctly in that patient's speech, this would point to an error in a particular module. Similarly, if two error types were highly correlated, this would count against the independence hypoth- 
esis. It is still possible within the model, for only one control oval to be affected. This would be hard to distinguish empirically from a disorder in the associated module, though in this latter case we would not expect to find constructions implicated in errors used correctly. Our data, however, indicate that all control ovals are similarly affected. ... Omissions have a natural control explanation: there could have been failure in initiation of lexical selection, or a loss in the transfer from lexical selection to phonological assembly.

Sentence blends could be due to a failure to terminate the operation of component processes when a candidate representation has been produced. Generally, one might expect information to be quite regularly lost in transfer from one module to another in aphasic patients, leading to a general underspecification of what is required by the dominated process and hence to unintended productions plus an insufficient specification for checking the production's appropriateness of correctness (see Butterworth and Howard, 1987, pp. 33-34, for further details). In brief, it is not assumed that normal grammatical errors (or other slips of the tongue) are due to a permanent disorder of a component process, but a transient failure in one of the control ovals' four functions could lead to them; hence, a global impairment of control should result in the same kinds of error, but occurring much more frequently.

Although Butterworth and Howard's data constitute good prima facie evidence against the first three classes of explanation, the positive evidence in favour of an impairment of control is weak in two important respects. First, as we indicated earlier, information about the intended grammatical structure of English utterance depends very largely on word-order. There is usually no way of telling whether a word is intended as a noun or verb. Butterworth and Howard, as a methodological principle, gave patients "the benefit of the doubt" in utterances where there was ambiguity. Because their argument rests critically on the distribution of error types, systematic misassignments could produce significant artefacts in the distributions. For this reason, we have chosen to study a patient who speaks Italian, which is a language with a rich inflexional system that provides better evidence for grammatical structure, especially in the speech of patients where neologisms and constituent order errors make intended grammatical structure difficult to establish. In Italian, verbs and nouns, for example, are frequently distinguishable on morphological grounds. While it is true that the final phoneme of the overwhelming majority of nouns, verbs and adjectives will be either $-\mathrm{a}$, -e, -i or $-\mathrm{o}$, certain endings are almost always found just on verbs (e.g. -éssimo, -eránno, -evámo, -ereste, -erebbe, etc.). Usually, it will be possible to use lexical, positional and morphological information to determine with confidence the intended grammatical category and number, gender or person, as relevant.

Intended phrase mates are marked not only by word order, as in 
English, but by infexional agreement among the words. In NPs, the determiner, the adjective and the noun must agree in both number and gender (1):
(1) la testa rossa
the head red
f.sg f.sg f.sg
gli alberi verdi
the trees green
m.pl m.pl m.pl

Morphological form provides a good clue as intended NP mates even where the head noun is a neologism. In "le lassotesse" (see 3d), the neologistic noun takes the usual feminine plural ending, and appears to agree with the feminine plural determiner, "le". Similarly, agreement in number, and sometimes gender, between subject NPs and VPs is obligatory and relatively transparent. In (2), the verb agrees in number and person with the subject, where an English version would not distinguish forms of the future tense by number or person:

(2) I bambini mangeranno la torta the children will eat the cake m.pl m.pl pl f.sg

In (3), the reflexive verb dimenticarsi requires the participle to agree in both number and gender with the subject:

(3) la ragazza si è dimenticata la lettera
the girl
f.sg f.sg 3.sg refl. Aux past part.f.sg

Getting agreement right depends on the correct functioning of component "microprocesses": like constructing a grammatical representation that links in the appropriate way the head and the modifier(s) that must agree-e.g. the head $(\mathrm{N})$ and the determiner and adjectives (modifiers) of a NP, or subject NP, the relevant parts of the VP (head) and the subject NP (modifier) of a sentence or clause-and selecting the appropriate inflexional forms of the relevant elements. Inflexional errors may, therefore, be a sensitive indicator of impairments in grammatical processes.

Using Italian data also allows us to explore more thoroughly Garrett's claim that closed-class words and grammatical morphemes are handled by the same process(es), as some closed-class words, like pronouns and determiners, are themselves extensively inflected.

The second important caveat to Butterworth and Howard's (1987) conclusions is prompted by their exclusive use of samples from a single testing date. The performance of aphasic patients is not static, but changes over time through the recovery of function and through the development of strategies for coping with the aphasic difficulties (cf. Panzeri, Semenza, \& Butterworth, 1987). Butterworth and Howard, like most researchers in 
this area, selected for study an arbitrary time-slice in the evolution of each patient's condition. These data provide a relatively weak test of a control impairment explanation. Provided all patients produce all types of error, and provided that there is no correlation between comprehension and error rates, then there is a presumption in favour of an impairment of control. However, some types are more frequent in one patient than in another. Nothing in the data from a single time-slice can tell us about the causes of these distributions. The appearance of a more frequent error type in one patient could be due to some sampling artefact, or it could be due to an impairment of a component process, making a particular type of error more likely in that patient-a fact of no theoretical relevance given that he makes other types of error. It may be, indeed, that the spread of errors is due not to a global control impairment, but to small deficits in several component processes, along with a big deficit in one component process. Now, if the speech of this patient was studied longitudinally, over many months, it may well turn out that some types of error disappear whereas others remain. This may be because the small deficits recover, whereas the big deficit does not; or because the deficits recover at different rates; or because ways are found to compensate for some deficits, but not others. In any of these cases, the different error types will appear in different proportions at successive sampling dates, perhaps with one type diminishing and another staying constant, even though all types may continue to occur. Thus a more stringent test of the control impairment hypothesis would be possible with longitudinal data.

To this end, we report on a longitudinal study of one fluent Italianspeaking patient, R.B., using the same methods and error categories as Butterworth and Howard, but in addition paying particular attention to inflexional morphology. If the control impairment hypothesis is correct, we would expect to find no consistent trends for particular error types. However, if the patient does show a trend in one type, or a few types, then one has to reconsider an explanation in terms of an across-the-board impairment of control.

\section{CASE REPORT}

R.B. was a 66-year-old right-handed businessman, with a high school education, speaking Florentine Italian (which is considered standard Italian). Before his accident he was able to speak French and German very competently and English less well.

In June 1986, he suffered an infarction of the left middle cerebral artery. A CAT scan indicated a large hypodense temporoparietal area. After a month in a peripheral hospital, he was transferred to the Neurology Department of Padova Polyclinic where he came to our attention. Apart 
from linguistic damage, a neurological examination showed a right-sided hemianopsia. He was partially anosognosic. He realised that his language was impaired, and occasionally was frustrated by his inability to name. He did not, however, have a full understanding of the severity of his impairment. He disliked speech therapy and, when dismissed from the hospital, he attended sessions only very irregularly. His mood varied from a slight depression to a decidedly excited state. In contrast to this, his premorbid personality was reported as being free from major emotional disturbances. He was a very uncooperative patient and formal testing with him was a rather difficult enterprise. On the other hand, he was very keen to offer examiners long pieces of uninterrupted jargonaphasic speech, whose rather empty content seemed to be concerned mainly with moral and nostalgic topics. Several attempts at formal linguistic testing with the Italian version of $\mathrm{BDAE}$ and the Token Test failed due to his uncooperative attitude. This is probably the cause of zero scores on most of the subtests of the BDAE. Word repetition seemed the only partially spared function, scoring 6 out of 12 (no length effect), along with word discrimination (20/72). However, when testing was less formal and occasional short naming trials were given, he clearly showed how deep his anomic defect was; while sentence comprehension appeared to be partly sensitive to the context.

His writing, while mechanically correct, was jargonaphasic. He never wanted to write on dictation. His reading was partially preserved when asked to read a newspaper, while on formal testing for reading simple words his score was 1 out of 30 . His reading "errors" were confabulations or refusals and could not be classified.

That both emotional behaviour and real impairment contributed to his linguistic performance is probably shown by the fact that it was possible to give him non-linguistic tests like RAVEN Matrices (the 1947 version) - on which he scored 18 out of 36 at the time of our first recording of his speech and 29 out of 36 a month later, which is average for his age, but lower than would be expected given his educational background and occupation-and Corsi's test, which he performed normally.

\section{METHOD}

Four samples of spontaneous conversational speech were collected at 2, 3, 4 and 9 months following the infarct. In each, conversation was prompted by general questions, and the patient was encouraged to talk freely. Careful transcripts were made of all the samples, with non-words recorded in broad phonetic transcription.

Grammatical errors were noted (see below for full details), as were neologisms in each sample. Table 1 gives the number of word-like seg- 
TABLE 1

The Corpus Analysed: The Number of Words, Together with the Incidence of Neologisms and Paragrammatisms in the Samples

\begin{tabular}{cccccc}
\hline $\begin{array}{l}\text { Months } \\
\text { after } \\
\text { Onset }\end{array}$ & $\begin{array}{l}\text { Words in } \\
\text { Samples }\end{array}$ & Neologisms & $\begin{array}{l}\text { Neologisms/ } \\
\text { 1000 Words }\end{array}$ & Paragrammatisms & $\begin{array}{l}\text { Paragram- } \\
\text { matisms/ } \\
\text { I000 Words }\end{array}$ \\
\hline 2 & 3139 & 118 & 37.5 & 71 & 22.6 \\
3 & 2401 & 29 & 12.0 & 50 & 20.8 \\
5 & 2386 & 25 & 10.4 & 36 & 15.1 \\
9 & 3478 & 10 & 2.8 & 85 & 24.4 \\
\hline
\end{tabular}

ments (real words and neologisms) in each sample, along with the number of grammatical errors and neologisms.

Speech error analysis suffers from the notorious problem that a given error may be interpreted in several ways (Cutler, 1982). Following Butterworth and Howard (1987), we adopted a conservative strategy in assigning errors to our categories.

Strings falling into more than one .. category [were assigned to] the most lexical. That is, if a string could be explained by the substitution, omission or addition of a single word or inflexion, this was the preferred classification (Butterworth \& Howard, 1987, p. 12).

Three judges (M.P., C.S. and T.F.) assessed each error assignment independently, and sought agreement on the few cases where these assignments differed. Where we had to choose between classifying an error as the selection of an incorrect word or the omission of a word, we opted for the former (see Butterworth \& Howard, 1987, for examples). Errors involving the use of derivational morphology on real words were assigned to the category "Open Class Errors" (see below). Further analysis of these errors can be found in Panzeri, Semenza, Ferreri, and Butterworth (in press).

Phonemic distortions and neologising may give rise to what have been called "jargon homophones" (Butterworth, 1979); these are in essence phoneme strings that just happen to sound like words. Although the distinction between these and real words is clear in principle, it is virtually impossible to draw in practice, and depends upon untestable assumptions about the intended target. All the dubious cases were classified as the real words they sounded identical to.

\section{Analysis of Grammatical Errors}

We followed the analytic scheme of Butterworth and Howard (1987), in so far as it was applicable to Italian. 
Open-class Lexical Errors. These errors were where the substitution, omission or addition of a single term, verb, adjective or some adverbs rendered the sentence ungrammatical. Substitutions were further subdivided into errors that violated major category conditions (e.g. replacing a noun with a verb) and subcategory violations where the substitute is of the correct major category, but is syntactically inappropriate in context (e.g. an intransitive verb in a context with a direct object).

\section{Examples}

1a. Category: Di qualsiasi insegnare (insegnante)

Of any to teach (teacher)

Of any teach

(infinitive verb instead of a noun) (first sample)

1b. Subcategory: Miei figli anche sono ingegneria (ingegneri)

My sons as well are engineering (engineers)

Also my sons are engineering (engineers)
(common name for object instead of person) (fourth
sample)

(Note: this cannot be explained as the omission of the word in (in), because "in ingegneria" (in engineering) is generally incorrect in Italian, except in the context, "laureati in ingegneria"-graduated in engineering-where it would be acceptable.)

1c. Omission: Come si chiama quel_lontano, qui? (paese)

It itself calls that_far, here? (country)

How do you say that far , here? (country)

(omission of noun with two determiners) (fourth sample)

1d. Addition: Si, ora non so dire, cosa dire, vede.

Yes, now not know to say, what to say, you see.

Yes, now I don't know to say, what to say, you see.

(addition of a verb after a modal) (first sample)

Closed-class Errors. These errors similarly comprised the substitution, omission or addition of a single word, in these cases of pronouns. prepositions, conjunctions, some adverbs (e.g. "molto", "solo") and articles. Substitutions were again subdivided into "category" errors, where, for example, an article substitutes for a preposition as in (2a), and "subcategory" errors, where the correct category is selected but the wrong exemplar is chosen (2b illustrates the use of an incorrect preposition). 


\section{Examples}

2a. Category: Fatto questo lavoro, si va la colazione. (a) Done this work, one goes the lunch. (to) When the work is done, one goes the lunch. (to) (article instead of preposition) (second sample)

2b. Subcategory: Vede, in questo momento sono a difficoltà (in) You see, at this moment I am to difficulty (in) You see, at this moment I am to difficulty (in) (wrong preposition) (first sample)

2c. Omission: E po-dopo mi hanno care-caricato And th- then me (they) have care-put subito — gli aerei per l' Italia. (su) at once _ the aeroplanes to (the) Italy. (on)

And the - then they put me at once_the aeroplanes to Italy. (on) (omission of the preposition) (first sample)

2d. Addition: Son già più di un mese che non lo Are already more than one month that (I do) not it guardo più niente, non voglio guardar watch anymore anything, (I do) not want to watch più niente anymore anything.

It is already more than one month since I watched it anything anymore, I don't want to watch anything anymore.

(addition of a pronoun with NP also present) (first sample)

Because articles and pronouns are inflected in Italian, inflexional errors of these words are counted as inflexional errors rather than as errors in the selection of a closed-class word. Thus using $i l$ (the m.sg) instead of la (f.sg) or i/gli (m.sg) would count as inflexional errors.

Inflexional Errors. Italian has a more extensive system of inflexions than English, with agreement of number and gender obligatorily marked by affixes on a wide range of constructions-determiner-noun, adjectivenoun, subject-verb, subject-verb complement. Word-formation rules require affixes on all conjugations of verbs, and all declensions of pronouns, 
adjectives and nouns (with a very few exceptions almost completely confined to loan words). In principle, inflexions could be omitted leaving a bare stem (port-are, *port), but this would not sound like a real word at all, and is found neither in R.B. nor in any other speech errors by normals (cf. Magno-Caldognetto, Tonelli, \& Pinton, 1987) or by aphasics (see Miceli, Mazzucchi, Mann, \& Goodglass, 1983; Miceli et al., 1989). Following Matthews $(1974$, p. 44), we assume that, because gender is often semantically arbitrary, the determiner and adjective agreement depends on the noun, as if the noun had to be chosen before the form of the determiner and/or adjective was fixed. That is to say, where agreement between determiner and/or adjective and noun fails, the error is assigned to the determiner and/or noun category.

The errors can be divided into three kinds. In the first, real words are in constructions such that they do not agree, as in the example,

3a. le compagni (i)

the partners

(f.pl. instead of m.pl. article) (second sample)

where the article is f.pl. and the noun is $\mathrm{m} . \mathrm{pl}$. A more complicated case is $3 b$,

3b. $i$ luci (le)

the lights

(m.pl. instead of f.pl. article)

where the gender of the noun is $\mathrm{f}$., but is expressed irregularly by the usual m.pl. affix. It appears that the article is made to agree with the superficial gender of the head noun, rather than its deep (i.e. true) gender. A second kind is where agreement is maintained but a real inffexion on a real stem yields a nonword. For example, in

3c. certi giornati (certe giornate)

certain days

(m.pl. instead of f.pl. adjective and noun) (second sample)

the plural of giornata should be giornate (f.) (giornati is a nonword) and the adjective should agree, as certe. Both words in the utterance have m.pl. affixes. The third kind adds an inflexional affix to a nonword, neologistic stem. These may either be correct,

3d. le lassotesse (/las:o'tes:e/)

the /las:o'tes:e/

(f.pl. article and noun) (first sample) 
where $-e$ is the standard f.pl. ending, and le the f.pl. article; or, incorrect,

3e. $i$ taitismo (/tai'tizmo/)

the /tai'tizmo/

(m.pl. article with m.sg. noun) (first sample)

where $i$ is the m.pl. article, and -o the standard m.sg. ending.

Constructional Errors. These are errors that cannot be explained by the substitution, omission or addition of a single word, or by failure of agreement. Some of these involve the misordering of words. For example:

4a. E di anche serietà (e anche di serietà)

And of also seriousness (and also of seriousness)

(preposition before adverb) (third sample)

Like Butterworth and Howard, we found relative clause gaps illegally containing filled NPs:

4b. Per assistere i miei figli, che $l i \quad$ facevo studiare.

To help (det.) my sons, whom them (I) made to study.

To help my sons, whom I made them study.

(presence of both relative and personal pronouns) (second sample)

We also found errors that could be explicated in terms of the blending of two well-formed alternatives (see Fay, 1982). For example:



Naturally, some utterances seem to fall into more than one of our error categories. Here is an error that we classified as a substitution sentence blend category, but also falls into the closed-class addition and the openclass substitution categories as well:

4d. Professori di universitari (adj.) professori DI UNIVERSITA' (n.) professori UNIVERSITARI (adj.)

Professors of university

(first sample) 


\section{RESULTS}

A total of 242 paragrammatisms were detected. To adjust for sample size, the rates for each error type according to the categories described above are given in Table 2.

There is no overall tendency for the rate of paragrammatisms to decline over time, unlike the rate of neologisms, which reduces to less than onetenth of its original rate in this period (see Table 1). The rate of speech, calculated as word-like segments per minute, increases consistently over time (see Table 2), suggesting an overall improvement in the ability to speak, and suggesting also that the reduction in neologisms is not a function of changing the speed/accuracy criterion.

As with Butterworth and Howard's (1987) patients, errors are observed in all the categories analysed. The types of error observed in R.B. are also found in the corpus of errors based on the speech of 50 normal subjects (Panzeri \& Semenza, 1988; Panzeri et al., in press). In general, the different types of error show no systematic trend.

\section{Open-vs Closed-class Errors}

One noteworthy and surprising feature of these results is that the rate of closed-class errors is nearly seven times greater than the rate of open-class errors. In all patients reported by Butterworth and Howard, the rates for the two types were roughly equal. This is not due to some peculiarity of R.B.'s speech: The proportion of closed-class words was identical to the norm for Italian (58\%: Semenza, 1986). However, the proportion of closed-class words in English (43\%: Francis \& Kucera, 1982) is substantially lower than in Italian, though the methods of counting were not strictly equivalent. Even so, this distributional discrepancy is insufficient to explain the difference in R.B.'s rate of closed-class errors. It is also possible that we have depended more on closed-class words to define the

TABLE 2

The Rate of Word-like Segments per Minute

\begin{tabular}{lllll}
\hline & \multicolumn{4}{c}{ Months after Onset } \\
\cline { 2 - 5 } & 2 & 3 & 5 & 9 \\
\hline $\begin{array}{l}\text { Word-like segments } \\
\text { per minute }\end{array}$ & 139 & 142 & 155 & 168 \\
\hline
\end{tabular}


structure of sentences containing errors, thereby making the closed-class words more likely to be accused of creating the error.

Notice also that neither Table 3 nor Table 4 shows a correlation by rates or proportions between closed-class errors, inflexional errors or constructional errors.

\section{Inflexional Processes}

Although R.B. makes a substantial number of infiexional errors, most of his inflexions are in fact correct in context. A noteworthy feature of this error category is that there does appear to be a trend for inflexional errors to decrease over time (Mann Test for Trend, $S=6, P<0.05$ ), but no such trend is seen for the other three error categories. (At first sight, there also appears to be a trend in constructional errors; however, the numbers involved are very small-11 in all-and the difference in rate between the 2 and 3-month samples is tiny, as it is between 5 and 9 months.) $A$ trend in just one category of error would clearly pose a problem for the control impairment hypothesis, which predicts that all error types will behave longitudinally in the same way. However, the rate of errors per number of

TABLE 3

Paragrammatisms/1000 Word-like Segments

\begin{tabular}{|c|c|c|c|c|c|}
\hline \multirow[t]{2}{*}{ Error Type } & \multicolumn{5}{|c|}{ Monlhs after Onset } \\
\hline & 2 & 3 & 5 & 9 & Torals \\
\hline \multicolumn{6}{|l|}{ Open-class } \\
\hline Category & 1.0 & 0.0 & 0.4 & 0.6 & 0.5 \\
\hline Subcategory & 0.0 & 0.8 & 0.0 & 0.3 & 0.3 \\
\hline Omission & 0.0 & 0.0 & 0.0 & 2.6 & 0.8 \\
\hline Addition & 0.3 & 0.0 & 0.0 & 0.0 & 0.1 \\
\hline Total open-class & 1.3 & 0.8 & 0.4 & 3.5 & 1.7 \\
\hline \multicolumn{6}{|l|}{ Closed-class } \\
\hline Category & 1.0 & 0.4 & 0.0 & 0.3 & 0.4 \\
\hline Subcategory & 2.5 & 0.8 & 0.8 & 0.6 & 1.2 \\
\hline Omission & 3.5 & 5.0 & 3.8 & 7.8 & 5.2 \\
\hline Addition & 2.5 & 4.2 & 2.1 & 5.5 & 3.7 \\
\hline Total closed-class & 9.5 & 10.4 & 10.5 & 14.2 & 10.5 \\
\hline Inflexional & 10.5 & 8.3 & 7.1 & 6.3 & 8.1 \\
\hline Constructional & 1.3 & 1.2 & 0.8 & 0.6 & 1.0 \\
\hline Totals & 22.6 & 20.7 & 15.0 & 24.6 & 21.2 \\
\hline
\end{tabular}


TABLE 4

Percentage Distribution of Paragrammatisms

\begin{tabular}{lrrrrr}
\hline Error Type & \multicolumn{5}{c}{ Months after Onset } \\
\cline { 2 - 6 } & \multicolumn{1}{c}{2} & \multicolumn{1}{c}{3} & 5 & 9 & Totals \\
\hline Open-class & 4.22 & 0.00 & 2.78 & 2.35 & 2.47 \\
Category & 4.22 & 0.00 & 2.78 & 2.35 & 2.47 \\
Subcategory & 0.00 & 4.00 & 0.00 & 1.18 & 1.24 \\
Omission & 0.00 & 0.00 & 0.00 & 10.59 & 3.72 \\
Addition & 1.41 & 0.00 & 0.00 & 0.00 & 0.42 \\
Total open-class & 5.63 & 4.00 & 2.78 & 14.12 & 7.85 \\
Closed-class & & & & & \\
Category & 4.22 & 2.00 & 0.00 & 1.18 & 2.07 \\
Subcategory & 11.27 & 4.00 & 5.56 & 2.35 & 5.78 \\
Omission & 15.49 & 24.00 & 25.00 & 31.77 & 24.38 \\
Addition & 11.27 & 20.00 & 13.89 & 22.35 & 17.36 \\
Total closed-class & 42.25 & 50.00 & 44.45 & 57.65 & 49.59 \\
Inflexional & 46.49 & 40.00 & 47.21 & 25.88 & 38.02 \\
Constructional & 5.36 & 6.00 & 5.56 & 2.35 & 4.54 \\
Totals & 100.00 & 100.00 & 100.00 & 100.00 & 100.00 \\
\hline
\end{tabular}

words, as presented in Table 3, does not take into account varying levels of overall accuracy at the different sampling dates. In Table 4, we present data for each error category as a proportion of the total errors. It can be seen that, analysed this way, there is no tendency for the proportion of inflexional errors to decrease. Nor does any other error category show a consistent trend on this analysis.

Agreement. As was pointed out above, agreement is a sensitive measure of grammatical impairment, because getting agreement right involves

TABLE 5

Subject-Verb Agreement: Incidence and Percentage of Errors (in Parentheses), Correct and Undetermined

\begin{tabular}{lcccc}
\hline $\begin{array}{l}\text { Months } \\
\text { after } \\
\text { Onset }\end{array}$ & Errors & Correct & Undetermined & Total \\
\hline 2 & $11(2.5)$ & $409(92.7)$ & $21(4.8)$ & $441(100)$ \\
3 & $4(3.0)$ & $112(84.8)$ & $16(12.2)$ & $132(100)$ \\
5 & $3(0.9)$ & $307(93.6)$ & $18(5.5)$ & $328(100)$ \\
9 & $6(1.1)$ & $520(96.5)$ & $13(2.4)$ & $539(100)$ \\
\hline
\end{tabular}


TABLE 6

Subject-Verb Agreement: Errors as a Percentage of Determinable Opportunities, and Rate of Opportunities (per 1000 Word-like Segments)

\begin{tabular}{lcr}
\hline $\begin{array}{l}\text { Months } \\
\text { after } \\
\text { Onset }\end{array}$ & Percentage & Rate \\
\hline 2 & 2.6 & 140 \\
3 & 3.4 & 55 \\
5 & 1.0 & 137 \\
9 & 1.1 & 155 \\
\hline
\end{tabular}

the co-ordination of the correct syntactic structure and the selection of the lexical form appropriate for that grammatical structure. Given that agreement is such a pervasive phenomenon in Italian, we have concentrated our analysis on two of its main loci: agreement between articles and head nouns in NPs (see examples 1, 3a, 3d and 3e), and agreement between subject and verb (see examples 2 and 3 ). Notice that Italian is a pro-drop language, where a subject may be omitted in certain cases. Our analyses considered not only sentences where the subject (a full NP or a pronoun) was present, but also cases where the pro-dropped subject could be reliably inferred from context. In general, the subject is omitted only in cases where its identity is clear from the context. An error of subject-verb agreement was counted if any part of the VP phrase (auxiliary, modal or participle) failed to agree with its subject in person, number or gender, where relevant. In Table 5, the overall rates of agreement error between subject and verb are displayed, and in Table 6 these rates are presented adjusted for the number of opportunities for agreement error.

TABLE 7

Determiner-Noun Agreement: Incidence and Percentage of Errors (in Parentheses), Correct and Undetermined

\begin{tabular}{lrrrr}
\hline $\begin{array}{l}\text { Months } \\
\text { after } \\
\text { Onset }\end{array}$ & Errors & Correct & Undetermined & Total \\
\hline 2 & $10(4.0)$ & $223(89.2)$ & $17(6.8)$ & $250(100)$ \\
3 & $8(3.3)$ & $227(95.0)$ & $4(1.7)$ & $239(100)$ \\
5 & $6(2.7)$ & $212(96.8)$ & $1(0.5)$ & $219(100)$ \\
9 & $8(2.5)$ & $308(97.5)$ & $0(0.0)$ & $316(100)$ \\
\hline
\end{tabular}


TABLE 8

Determiner-Noun Agreement: Errors as a

Percentage of Determinable Opportuni-

ties, and Rate of Opportunities (per 1000

Word-like Segments)

\begin{tabular}{lcc}
\hline $\begin{array}{l}\text { Months } \\
\text { after } \\
\text { Onset }\end{array}$ & Percentage & Rate \\
\hline 2 & 4.3 & 80 \\
3 & 3.4 & 99 \\
5 & 2.8 & 92 \\
9 & 2.5 & 91 \\
\hline
\end{tabular}

If we look at the errors as a percentage of the number of subject-verb combinations (opportunities), rather than as the rate of errors per 1000 words, as presented in Table 3 , does not take into account varying levels of agreement, the trend is an artefact of the rate measure: opportunities are not equivalent for each sample. This is brought out clearly in the rate column in Table 6. For some reason, the rate of subject-verb combinations varies considerably from sample to sample. Nevertheless, there appears to be a decline in errors after 3 months. A similar analysis was carried out for determiner-noun combinations, and the results are displayed in Tables 7 and 8 . Here the correction for the number of opportunities does not eliminate the consistent trend over samples-the proportion of errors decreases from sample to sample. Looking at Table 7, the reason becomes clear, i.e. the rate of opportunities is fairly constant across samples.

\section{Intact Grammatical Performance}

Evidence relevant to the four classes of explanation we outlined in the Introduction comes not only from what R. B. fails to do, but also from what he is able to do.

Inflexional Processes. The preservation of inflexional processing comes out most clearly when it cannot rely on known forms, i.e. when R.B. uses inflexions on neologistic stems. Here, 177 out of 182 neologisms were correctly inflected. A total of 22 different types of inflexional endings were correctly deployed. This includes all the possible declensions of nouns (and adjectives) and the most frequent, and some infrequent, types of conjugations on verbs. 
Syntactic Processes. Here again, despite the paragrammatisms tabulated above, clauses are overwhelmingly syntactically correct. Even complex constructions are regularly produced correctly, as can be seen from the following examples:

6a. E è rimasto bloccato perché, i-, quando ebbi

And (it) is left blocked because, i-, when (I) had

quell'/intos:i'mento/, dovetti prender gli aerei e that /intos:i'mento/, (I) had to take the aeroplanes and

ripartire subito.

depart at once.

And it was left blocked because, i-, when I had that /intos:i'mento/, I had to take the aeroplanes and depart at once.

(Intact: subordinate clause embedding; sequences of tenses)

(first sample)

6b. Istintivamente mi si bloccherebbe, e stop, basta,

Instinctively to me itself would block, and stop, enough, (I)

non devo rispondere, perché potrei sbagliare.

not have to answer, because (I) could mistake.

Instinctively it would block me, and stop, that's enough. I don't have to answer, because I could make a mistake.

(Intact: conditional; reflexive pronoun, left dislocation with indirect pronoun; sequence of tenses) (third sample)

6c. Durante la guerra ero ragazzo, quando mi nacque un During the war (I) was (a) boy, when to me born a

figliolo, nel '44, io l' ho avuto nel '43; i tedeschi

son, in 1944. I him had in 1943; the Germans

mi rispettarono salutandomi, quando partirono, e

-me respected saluting me, when (they) left, and

oggi sono comandanti anche loro.

nowadays are commanders also they.

During the war I was a boy, when a son was born to me, in 1944. I had him in 1943. The Germans respected me saying goodbye to me when they left, and nowadays they as well are commanders.

(Intact: sequence of tenses; direct and indirect personal pronoun, left dislocation; personal pronoun enclitic position) (fourth sample) 
6d. Pranza con attenzione, non fa cascar la cosa;

(He) eats with care, not makes drop the thing;

vedessi che manine veloci, proprio forti, (could you) see what little hands quick, quite strong,

potenti: è un sogno!

powerful: (it) is a dream!

He eats carefully, he does not drop the thing. Could you see what quick little hands he has, really strong, powerful. It's a dream! (Intact: subjunctive) (fourth sample)

\section{DISCUSSION}

In this study, we have analysed four samples of spontaneous speech from an Italian aphasic patient spread over 7 months. Broadly, R.B.'s speech is similar to that of the patients described by Butterworth and Howard, and longitudinal data from him provide a new way of assessing accounts of the deficits underlying paragrammatical speech production.

It is possible to extrapolate longitudinal predictions from the four classes of explanation of paragrammatical speech considered in the Introduction.

\section{The Syntactic Deficit Hypothesis}

Like Butterworth and Howard's patients, R.B. was able to use correctly grammatical processes that, on occasion, led to error: He could select words of the appropriate grammatical category and subcategory, he could produce correctly long and complex sentences, and he was usually in control of inflexional processes. All these facts indicate that the relevant rules and procedures for their application are intact.

On the other hand, unlike Butterworth and Howard's patients, the preponderance of single word errors involved function words, and a large number of inflexional errors. Both function words and inflexions are specifically linked to grammatical construction, rather than to lexical processes, according to Garrett (1982). However, on Garrett's account, both function words and inflexions have a common source at the "positional level" in his model. Both function, closed-class words and grammatical morphemes are inserted into the sentence frame so as to define the grammatical structure of the utterance. If this level is impaired, one would expect the longitudinal picture to be the same for both. Neither closedclass errors nor inflexions show a consistent trend over time, nor are the error or error proportions correlated, one with the other or with errors of 
syntactic construction. Clear support for Garrett's model would have been found if any of these correlations had been osberved; however, the lack of correlation between just four data points is insufficient to reject a close relation between the use of closed-class words, inflexions and syntactic processing. Interestingly, in his elaboration of Garrett's model, Lapointe (1985) separates inflexions from function words: the former being attached to fragments of phrase structure, retrieved from a store of fragments, whereas the latter are held in a special store. This separation allows him to explain why agrammatic aphasics substitute simpler inflexions for more complex ones, while omitting, rather than making substitution errors for, function words: Agrammatics suffer an overall deficit in resource allocation to syntactic processing, and the little that is available has priority allocation to retrieving fragments, and then only the simpler types, leaving no resources to allocate for retrieving function words.

\section{The Lexical Deficit Hypothesis}

This predicts that the kind of word most likely to be implicated in error are those most difficult to retrieve, which we know from many other studies to be low-frequency words, typically nouns, verbs and adjectives. We have seen that the reverse is the case for R.B. Moreover, to the extent that neologisms reflect a word-finding problem, then the decline in neologistic output should correlate with a decline in paragrammatic errors. It does not.

\section{The Monitoring Impairment Hypothesis}

If paragrammatic output depends on failing to detect and edit out errors before they are uttered, then as monitoring functions recover, all error types should show a reduction-not necessarily at the same rate though, as some error types may be more difficult to detect or correct than others. We have seen that there appears to be a reliable trend for two types of errordeterminer-noun agreement and neologisms - but not for the others. We must conclude, therefore, that productive rather than monitoring processes are responsible for the pattern of errors observed. Nevertheless, as was pointed out earlier, the appearance of errors in speech will depend on the underlying rate of error production and the efficiency of the monitor, and the monitor may find some types of error easier to detect than others. However, because we currently have no way of estimating the underlying rate of error production independently of observed errors, nor of determining which types of error are easiest to detect, we must wait upon the development of monitoring theory before reconsidering this possible explanation. 


\section{The Control Impairment Hypothesis}

This predicts that the kind of unit and construction implicated in error would also be used correctly. We have seen that this is the case for all error types-inflexions, even on neologisms, complex constructions, closed-and open-class words - and they are all produced without grammatical error in the overwhelming majority of instances. This account requires also that errors are of the same types as are found in normal slips of the tongue. Unfortunately, there is nothing like the same body of data on Italian slips as there is on English or German slips; nevertheless, the types of error we report do fall into the same categories as have been observed in one Italian corpus (Panzeri \& Semenza, 1988; Panzeri et al., in press) and corpora from speakers of other languages, and are presumably due to the same transient malfunctions of control.

The overall distribution of errors reflects language-specific properties of Italian, and freer word-order means that fewer constituent ordering errors will result in ungrammaticality; a richer inflexional system offers more opportunities for inflexional error, in particular, errors of gender agreement which could not arise in English.

Using longitudinal data provides additional investigative resources for identifying functional connections and dissociations that is impossible with a single sample. Thus we observed a trend in inflexional errors on determiner-noun agreements, but in no other grammatical processes. This trend correlated with a reduction in neologisms, suggesting that inflexional production may be more closely linked with lexical processes than with syntactic processes. This, however, is speculation. A more detailed analysis of morphological processes in R.B. may yield firmer evidence (Panzeri et al., in press).

\section{Paragrammatism and Agrammatism}

The distinction between these two disturbances of aphasic speech is traditionally characterised in descriptive terms: In the first, syntax and morphology are confused and erroneous; in the second, these features are simplified or omitted. However, there has been little or no attempt at formulating a theoretical distinction. Certainly, the association between the symptoms of paragrammatic output and impaired comprehension and posterior lesion site has suggested to many authors a syndrome that is explicable in terms of a localisationist model; but, as has been pointed out by Butterworth and Howard (1987), these symptoms do not reliably hang together. Recently, Miceli et al. (1989) have noted that some Italian agrammatic patients produce as many substitution as omission errors of free-standing grammatical morphemes, making a distinction between di- 
agnostic groups based on omission vs substitution criterion very problematic. Generally, it is nowadays agreed that agrammatism comes in several distinct varieties (see Badecker \& Caramazza, 1985; Howard, 1985; Kolk \& van Grunsven, 1985; Miceli et al., 1989).

Paragrammatic patients, as we have seen from Butterworth and Howard's study and from our own here, also show a variety of additional deficits of comprehension and a variety of lesion sites in the parietal as well as the temporal lobes of the left hemisphere (see also Panzeri \& Semenza, 1988). Nevertheless, our best guess at present as to the cause of the grammatical disturbance of their speech is in terms of across-the-board impairment of control.

Manuscript received February 1989

Revised manuscript received October 1989

\section{REFERENCES}

Badecker, W. \& Caramazza, A. (1985). On consideration of method and theory governing the use of clinical categories in neurolinguistics and cognitive neuropsychology: The case against agrammatism. Cognition, 20,97-125

Bradley, D. C., Garrett, M. F.. \& Zurif. E. (1980). Syntactic deficits in Broca's aphasia. In D. Caplan (Ed.), Biological sudies of mental processes. Cambridge, Mass.: MIT Press.

Butterworth. B. (1979). Hesitation and the production of verbal paraphasias and neologisms in jargon aphasia. Brain and Language, $8,133-161$.

Butterworth, B. (1980). Some constraints on models of language production. In B. Butterworth (Ed.), Language production, Vol. 1. London: Academic Press.

Butterworth, B. (1982). Speech errors: Old data in search of new theories. In A. Cutler (Ed.), Slips of the longue and language production. The Hague: Mouton.

Butterworth, B. (1985). Jargon aphasia: Processes and strategies. In S. Newman \& R. Epstein (Eds), Current perspectives in dysphasia. Edinburgh: Churchill Livingstone.

Butterworth, B. \& Howard. D. (1987). Paragrammatisms. Cognition, 26. 1-37.

Cutler, A. (Ed.) (1982). Slips of the tongue and language production. The Hague: Mouton. de Bleser, R. (1987). From agrammatism to paragrammatism: German aphasiological traditions and grammatical disturbances. Cognitive Neuropsychology. 4, 187-256.

Fay, D. (1982). Substitutions and splices: A study of sentence blends. In A. Cutler (Ed.), Slips of the tongue and language production. The Hague: Mouton.

Francis, W. M. \& Kucera, H. (1982). Frequency analysis of English usage: Lexicon and grammar. Boston: Houghton Mifflin.

Fromkin, V. A. (1973). Speech errors as linguistic evidence. The Hague: Mouton.

Fromkin, V. (1980). Errors in linguistic performance: Slips of the tongue, era, pen, and hand. London: Academic Press

Garrett, M. F. (1975). The analysis of sentence production. In G. Bower (Ed.), Psychology of learning and motivation, Vol. 9 . London: Academic Press.

Garrett, M. F. (1980). Levels of processing in sentence production. In B. Butterworth (Ed.). Language production, Vol. 1. London: Academic Press

Garrett, M. F. (1982). Production of speech: Observations from normal and pathological language use. In A. Ellis (Ed.), Normality and pathology in cognitive functions. London: Academic Press. 
Howard, D. (1985). Agrammatism. In S. Newman \& R. Epstein (Eds), Current perspectives in dysphasia. Edinburgh: Churchill Livingstone.

Isserlin, M. (1922). Über Agrammatismus (edited and translated by H. Droller, D. Howard, \& R. Campbell). In Cognitive Neuropsychology, 2, 304-345.

Kleist. K. (1916). Uber Leitungsafasie und grammatische Storunge. Monatsschrift für Psychiatrie und Neurologie. 16, 118-121.

Kolk, H. H. J. \& Van Grunsven, M. F. (1985). Agrammatism as a variable phenomenon. Cognitive Neuropsychology, 2, 347-384.

Lapointe. S. (1985). A theory of verb form use in the speech of agrammatic aphasics. Brain and Language. 24. 100-155.

Levelt. W. J. M. (1983). Monitoring and self-repair in speech. Cognition. 14. 41-104.

Levelt, W. J. M. (1989). Speaking: From intention to articulation. Cambridge, Mass.: MIT Press.

Magno Caldognetto. E., Tonelli, L.. \& Pinton. A. (1987). I morfemi radicali nella produzione della parola. Acta Phoniatrica Latina. 9. 373-380.

Matthews, P. H. (1974). Morphology: An introduction to the theory of word-structure. Cambridge: Cambridge University Press.

Miceli, G., Mazzucchi. A., Mann. L., \& Goodglass. H. (1983). Contrasting cases of Italian agrammatic aphasia without comprehension disorder. Brain and Language. 19, 65-97.

Miceli, G.. Silveri, C., Romani, C. \& Caramazza, A. (1989). Variation in the pattern of omissions and substitutions of grammatical morphemes in the spontaneous speech of socalled agrammatic patients. Brain and Language. 36. 447-492.

Newcombe, F., Oldfield, R. C.. \& Wingfield, A. (1965). Object-naming by dysphasic patients. Nature, 207, 1217-1218.

Panzeri. M. \& Semenza. M. (1988). Paragrammatisms in Italian: A study of five cases. Poster presented to the Academy of Aphasia, 26th Annual Meeting. Montréal. October.

Panzeri, M.. Semenza, C.. \& Butterworth. B. (1987). Compensatory processes in the evolution of severe jargon aphasia. Neuropsychologia. 25, 919-933.

Panzeri, M., Semenza, C. Ferreri, T., \& Butterworth, B. (in press). Free use of derivational morphology in an Italian jargonaphasic. In J.-L. Nespoulous \& P. Villiard (Eds). Morphology, phonology and aphasia. New York: Springer-Verlag.

Pick, A. (1931). Aphasia (translated by J. W. Brown). Springfield, IIl.: Charles Thomas.

Schwartz, M. F. (1987). Spoken language disorders from the psycholinguistic point of view. In M. Coltheart, R. Job. \& G. Sartori (Eds), The cognitive neuropsychology of language. London: Academic Press.

Semenza, C. (1986). L'esame della produzione afasica spontanea. Acta Phoniatrica Latina, $8,99-112$.

Shallice, T. (1988). From neuropsychology to mental structure. Cambridge: Cambridge University Press.

Weisenburg. T. \& McBride, K. E. (1935). Aphasia. New York: Commonwealth Fund. 